\title{
Milestones of the IAGA International Service of Rapid Magnetic Variations and its contribution to geomagnetic field knowledge
}

\author{
J. J. Curto, J. O. Cardús, L. F. Alberca, and E. Blanch \\ Ebro Observatory, Consejo Superior de Investigaciones Científicas (CSIC), Universitat Ramon Llull, Roquetes, Spain
}

(Received October 30, 2006; Revised January 18, 2007; Accepted January 18, 2007; Online published June 8, 2007)

\section{Introduction}

The Service of Rapid Magnetic Variations (RMV) was created by the International Association of Geomagnetism and Aeronomy (IAGA) with the aim of obtaining an overall view of the temporal and spatial distribution of RMV as a base for further study of these phenomena. The Ebro Observatory participated in the creation of this service and has been administering it from the beginning; consequently, the histories of these two organizations are intertwined.

The Ebro Observatory was the first observatory oriented to the study of Solar Terrestrial Physics research (Mathias, 1924). It was founded in 1904 (Cirera, 1906) and had been contributing valuable data to this area of research for more than 100 years. The contribution of the Observatory to the RMV Service has been twofold: (1) an internal one, in that the Observatory administers the practical day-today operations of the service, including determining which the parameters are to be observed, how the data are to be collected and how the results should be assessed and, if necessary, improved; (2) an external one, by studying the phenomena producing these data. A complete explanation of the evolution of the Service can only be given properly when the Service is placed in the context of the historical evolution of the scientific interest in RMV, and the evolution of the Association, as has been reported in the different meetings over the years that have brought scientists in this field together with the aim of interchanging ideas.

\section{History}

As it is well known, in October 1918, just before the peace treaty was signed that ended the First World War, the Conseil International de Recherches (at that time French was the official language), meeting in London, decided to create three 'Unions' as a means to support advances in the Sciences. The three Unions were those of Astronomy, Geodesy and Geophysics, and Radio Science. In July 1919, the International Union of Geodesy and Geophysics (IUGG) celebrated its first constituent meeting in Brussels. The statutes that were adopted in the Plenary Session included provisions for the creation of six 'Sections': Geodesy, Seismology, Meteorology, Terrestrial Magnetism

Copy right(c) The Society of Geomagnetism and Earth, Planetary and Space Sciences (SGEPSS); The Seismological Society of Japan; The Volcanological Society of Japan; The Geodetic Society of Japan; The Japanese Society for Planetary Sciences; TERRAPUB. and Electricity, Physical Oceanography, and Volcanography. The term 'Section' changed to 'Association' in the Lisbon Assembly held in September 1933. In the Rome Assembly of 1954, the designation of 'International Association of Terrestrial Magnetism and Electricity' (IATME) was changed to 'International Association of Geomagnetism and Aeronomy' (IAGA). The term 'Association' instead of 'Section' will be used in this article to refer to this Institution.

Based on the evolution of the interest of the Association for RMV, exemplified by the creation of the Service and the influence of various external circumstances, primarily the Second World War, three distinct periods in the history of the Service of RMV inside the Association can be distinguished. The first period is from 1919, with the creation of the Association, to 1939, with the General Assembly of Washington, just at the beginning of the Second World War, which disrupted the activity of the Association for several years. The second period extends from the end of the Second World War (with the Oslo General Assembly in 1948 as a reference), to the Rome General Assembly in 1954, when the Association decided to create the Committee No. 10 "for the study of Rapid Magnetic Variations and Earth Currents". The third period includes the period from the Rome Assembly until the present. During this long period the work of the Service of RMV has experienced many changes.

2.1 First period: creation of the Association (1919)Washington Assembly (1939)

In the first Assembly after the creation of the Association (Rome Assembly 1922) Fr. Rodés, at that time Director of the Ebro Observatory, introduced the problem of the non-simultaneity of sudden storm commencements (SSCs) (Fig. 1) (Bauer, 1923) and presented a tentative theory to explain this fact (Rodés, 1922). The question of the simultaneity or the propagation of SSCs was a debated issue at that time, in part because of the difficulty to obtain the accurate time of data with the instruments then available. In the following Assembly (Transactions of Madrid Assembly, 1924), a new 'Committee on Observatories, Instruments and Scheme of Operations for Observing Accurately Time of Occurrence of Sudden Commencements of Magnetic Storms' was created, and Prof. Tanakadate was appointed as Chairman of the Committee. He sent a Circular to the observatories with a questionnaire consisting of 


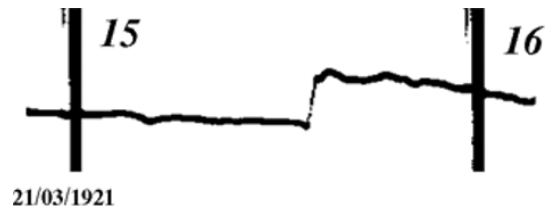

Fig. 1. Magnetogram of Ebro observatory corresponding to March 21, 1921, at which time there is an SSC at 15:35. The typical step function reflex of the increase of the dynamic pressure of the solar wind is present. A preliminary impulse produced by the rapid penetration of particles in the auroral zones by field-aligned currents precedes the main impulse.

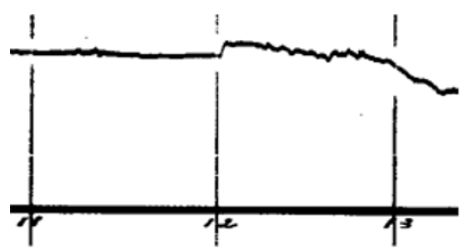

7/XII/1993

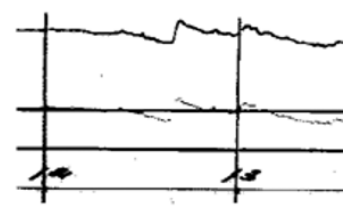

24/V/1983

Fig. 2. Two magnetograms recorded at the Ebro Observatory at real scale with an SSC. The precision in the determination of the time of occurrence depends on, among other things, the temporal development of the recorder. To improve this, in Ebro, the development was changed from $2 \mathrm{~cm} / \mathrm{h}$ (the standard) to $3 \mathrm{~cm} / \mathrm{h}$.

nine questions that can be considered to be the starting point of the regular work of the Association in RMV.

At that time some theories on SSCs predicted simultaneity of the SSC around the world, while other ones considered that it was a propagation of the events. Chapman (1917) proposed that the SSC was produced by a stream of ionized particles ejected by the Sun. This stream would have a transversal component of velocity equal to the velocity of the Sun's surface and could reach the earth and overtake it in about $30 \mathrm{~s}$. The first region of the earth affected should be that near the sunset meridian, with a propagation direction towards the east in the night hemisphere and towards the west in the dayside. Rodés' (1922) hypothesis was similar to that of Chapman's, but he considered that the velocity of the stream was radial from the Sun. With this model, the first region affected should be near the sunrise meridian, and the direction of propagation of the effect would be contrary to that of Chapman's theory. The time to cover the whole earth would be about $6.5 \mathrm{~min}$. Based on experimental data of several stations around the world, Bauer and Peters (1925) deduced that the effect propagates from the equator to the poles at $100 \mathrm{~km} / \mathrm{s}$. As can be seen, it was important to produce records where the initial moment of the event could be accurately determined.

In a report presented at the Prague Assembly (1927), Prof. Tanakadate informed the assembly that the Committee on Investigation of Sudden Commencements of Magnetic Storms had approved an instrument designed by Prof. Crichton Mitchell and constructed in Scotland, where it had been tried out under the direction of the designer. This report also described a new set of instruments, designed by D. Ono, and currently being tried out at Kakioka, which were able to record changes on highly disturbed days.

In the General Assembly of Stockholm (1930), the preparation for the collaboration in the II Polar Year began. This would have an important impact on the field of geomagnetism and on the future work of the RMV.

The work to improve the magnetographs continued. Dr. Ono presented the results of the observations taken with the equipment described in the Prague Assembly. Fr. Rodés, Director of the Ebro Observatory, reported on the first assays of the observatory to record the exact time of the SSC by deviating part of the light rays of the normal magnetographs towards a recorder with a faster revolution. Another topic discussed in this Assembly was the uneven distribution of magnetic observatories around the world that

made the study of phenomena as magnetic storms and other world-wide effects difficult to carry out. In terms of publishing data of the magnetic elements, it was emphasized that only about 60 observatories published all three elements, while about 12 gave only declination. In addition, there were observatories that only made absolute observations. As a result, a decision was taken to appoint a Special Committee 'To Consider Existing and Desirable Distribution of Magnetic and Electric Observatories and a Better Coordination of Work and Publications of Existing Observatories'.

The Assembly of Lisbon (1933), which was held at the end of the II Polar Year, reported an increase in the number of publications on SSCs. Eight papers related to SSCs were presented. Among these was a paper by Fr. Rodés (1934) on SSC diurnal, seasonal and secular periodicity. In this paper he acknowledged that the Chapman theory-and not his own-was in better agreement with the results.

Prof. Tanakadate as the Reporter of the Special Committee on Sudden Commencement of Magnetic Storms informed the Assembly that quick running magnetographs with a great economy of photographic paper had been constructed following the proposal of Dr. La Cour. Using records made with these magnetographs in Kakioka and Kanoya, Prof. Tanakadate selected three well-marked SSCs in $\mathrm{H}$ that had been carefully measured. He compared the results with similar measurements on records of other distant observatories and found only a few seconds of difference. He deduced that the same event was registered almost simultaneously in all stations with the individual characteristics depending on the local time. In the same report, he mentioned the difficulty of defining the exact initial point of the SSC, a problem not yet solved. Short temporal development in the recorders reduced the precision in the determinations (Fig. 2).

The name of Committee for the study of SSCs was changed to the 'Committee for the Study of Magnetic Storms with Sudden Commencement'. This committee comprised Prof. Tanakadate (President), S. Chapman, D. LaCour and Fr. Rodés.

The Assembly of Edinburgh (1936) was a turning point with respect to the interest of the Association for RMV. Although the Committee for the Study of Magnetic Storms had been disbanded, the first steps towards the establishment of what would become the RMV Service were taken. Two Committees - a Committee on 'the Registration in Ice- 
land of Giant Pulsations' and a 'Joint Committee of the Commission on Terrestrial Magnetism and Atmospheric Electricity (of the International Meteorological Organization, OMM), and of the IATME on Methods and Codes to Adequately Describe Magnetic Disturbances and Perturbations' were created. The Chairman of the latter Committee, Dr. J. A. Fleming, proposed a code-system of 5-number groups for broadcasting or telegraphing pulsations, oscillations, bays, gradual commencement, and sudden commencements of magnetic storms. It was also suggested that only a certain limited number of observatories representative of world conditions would be selected by the Commission to begin using the proposed codes. Fr. Rodés (1937), who was unable to attend the meeting because of the Spanish Civil War, sent a 'Report to the President of the Committee on Sudden Commencements' on research on the simultaneity or non-simultaneity of storm sudden commencements. He deduced that the highest temporal accuracy that could be obtained with the magnetometers currently in use was of the same order as the time differences of arrival of the perturbation that had to be measured. Therefore, great care should be taken by Observatories to keep the exact time in the records of time marks and in the measurements.

The General Assembly of Washington (1939) coincided with the commencement of the Second World War, so that only very few scientists from outside the USA and Canada (24) participated. Nevertheless, a new 'Committee on Three Hourly Indexes for the Magnetic Characterization' was created under the chairmanship of Prof. Bartels, and the continuation of the already established committees was agreed to.

\subsection{Second period: General Assembly of Oslo (1948)— General Assembly of Rome (1954)}

The General Assembly of Oslo (1948) represented the resumption of scientific activity in the field following the end of the Second World War.

The Joint Committee with the OMM was dissolved because of the termination of the 'Commission on Terrestrial Magnetism and Atmospheric Electricity'. Its work was entrusted to a new Committee, the 'Committee No. 9 on Magnetic Disturbances Characterization', chaired by Prof. Bartels.

Among the resolutions adopted by the Assembly, the resolution no. 8 asked the magnetic observatories to include in their publications a list of times of the sudden commencements of magnetic disturbances, and as far as practicable, the time of solar flare magnetic effects (Sfe), giant pulsations and other remarkable phenomena not followed by magnetic disturbance (Transactions of Oslo Meeting, 1950).

No important changes were recorded in terms of RMV during the Assembly of Brussels (1951), with the exception of the report on the general character of the law of classification of magnetic bays at mid latitudes, presented by Fr. Romañá (1954).

\subsection{Third period: General Assembly of Rome (1954)} onwards

As mentioned above the General Assembly of Rome (1954) approved changing the name of the Association from the 'International Association of Terrestrial Magnetism and
Electricity (IATME)' to the 'International Association of Magnetism and Aeronomy (IAGA)'.

It was decided to create a new Committee No. 10 on 'Rapid Variations and Earth Currents', and Fr. Romañá was elected as chairman. The task of the Committee was to continue the work on SSC, PSC, SI and SFE, which was formerly carried out by Committee No. 9 ('Characterization of Magnetic Activity'). Data were to be published in Bulletin 12, as previously carried out by Committee No. 9 (Transactions of Rome Meeting, 1957).

Fr. Romañá considered it essential to establish a new determination of the phenomena to be reported by observatories as well as a better definition of these in order that they fit better with the present level of knowledge and the new research lines. To achieve this, in the Brussels Meeting (1955) of the 'Special Committee for the International Geophysical Year (CSAGI)', he called for a meeting of the members of Committee No.10 who were present and other experts of the Working Group of Geomagnetism. The result of this meeting was a circular letter sent to all collaborating observatories, with new instructions on the phenomena to be reported and a request for comments on them (Transactions of Toronto Meeting, 1960). The following phenomena were defined:

- SSC (and SSC*), a sudden impulse followed by increased activity with storm characteristics for a sufficiently long period of storminess. SSC* is preceded by a sudden movement contrary to the principal.

- Psc, a sudden commencement-with or without pulsations - of a bay of sufficient amplitude - the amplitude depending on magnetic latitude_-during a relatively quiet interval.

- The indication SI was surpressed.

- Pulsations (p) were divided in two groups:

- pt, a series of pulsations of limited duration, usually less than $1 \mathrm{~h}$, often preceding or accompanying a bay disturbance.

- pc, a series of pulsations lasting for many hours.

- Sfe, a short daytime bay or crochet, generally in the sense of the daily variation, tentatively attributed to a solar flare.

In the CSAGI Meeting of Barcelona (1956), Fr. Romañá presented the results of half a year of experience using the new definitions and procedure to the Working Group of Geomagnetism. During the discussion, the members clearly saw the necessity of a new meeting of Committee No. 10 to select the phenomena to be reported by observatories and to clarify the definitions and the procedures to be reported. Fr. Romañá called for a Symposium which took place at Copenhagen in 1956. The President of IAGA, Prof. Bartels, and several invited experts in addition to the members of Committee No. 10 participated in the meeting. Fr. Cardús was appointed Secretary of the Symposium. Fr. Romañá indicated that a Symposium on the general problem of the rapid magnetic variations would be called at the end of the Geophysical Year, so that the present Symposium should be involved only in practical problems, and therefore he established norms to facilitate discussion. The Symposium produced a new list of phenomena that the observatories had 
to send monthly to the Committee. A distinction was made between rapid and normal run magnetograms. The list for the normal run magnetograms included: SSC, SSC*, SI, b, bp, bs, bps, pt, pg, Sfe. The SI was again included as a sudden impulse inside a storm when it was doubtful whether it was a new sudden storm commencement.

For the rapid magnetometers three types of pulsation were included: pt, pc, pg.

The symbols for the bays were defined as: b (bays), bp (bays with pulsations), bs (bays with sharp beginning), bps (bays with pulsations and sharp beginning) and bg (giant pulsations).

Two codes of letters were also proposed to indicate the clarity of the phenomena and the quality of the record.

It was also decided to publish an atlas with examples of the different kinds of phenomena, first a provisional one with artificial examples, and later, another one with real examples.

The recommended process to make the yearly definitive list of events was defined as follows: a list of events from the received data of all observatories (checking list) was prepared. In general, the list included all data, except for the Sfe, that needed a special procedure. All of the Sfe events that coincided with other magnetic events clearly established were suppressed from the Sfe list. The Sfe reported without confirmation for a unique observatory, while no movement was recorded by nearby observatories, was also suppressed from the list. The checking lists were sent to the collaborating observatories with the request to confirm and qualify the events. They were to be answered in a concerted way with a code of letters, as explained above. Global maps showing the illuminated and shadowed regions were made for every Sfe, and the region where the event was possible was determined. A synoptic study of the so$\operatorname{lar}(\mathrm{H} \alpha$ and $\mathrm{X}$ rays), ionospheric (SID), and radio-electric data was added to all of this. All of these data were to be used to make a final qualification of the reported events, which could be assessed as: (1) certain, (2) doubtful, or (3) rejected. The definitive lists of certain and doubtful Sfe, timely arranged, were then comprised. The starting time and the reporting observatories with the given qualification were included for each event. The inclusion of other events in the final lists depended on the number of reported observatories.

In the Report of Committee No. 10 for the General Assembly of Toronto (September 1957), Fr. Romañá insisted on the importance of a clear definition of the nature and morphology of the reported phenomena in order to avoid the risk of making the statistics not homogeneous enough and, consequently, not very useful. He also reported on the Symposium of Copenhagen and the resolutions adopted there. These resolutions were adopted by IAGA in Resolution 9 of the Assembly.

The Provisional Atlas of Rapid Magnetic Variations was also presented, although it was published later (Romañá, 1959). In several sessions of the Assembly, 12 Communications related to the rapid magnetic variations were presented.

The organization of the Symposium on Rapid Magnetic Variations, planned to take place at the end of the Inter- national Geophysical Year, was entrusted to Fr. Romañá. This Symposium was held at Utrecht (September 1959), and Fr. Cardús was elected Secretary. The best geomagnetic theoretical and experimental specialists participated. The former explained the latest theories and the data they needed to carry out their research, while the latter reported the actual limits of the possibility of observation. Several sessions were devoted to magnetic pulsation that had raised great interest, mainly among the Russian researchers. Unfortunately, these researchers could not go to the Symposium, but they sent their papers. The main topics were: Geomagnetic pulsations introduced by an introductory lecture by Prof. Coulomb (1959), Earth-current pulsations introduced by Prof. De Voogt (1959), SSCs introduced by Prof. Chapman (Akasofu and Chapman, 1959), and Solar-flare effects, introduced by Prof. Veldkamp (Veldkam and Van Sabben, 1959). Both the progress being made in terms of acquiring knowledge on the rapid magnetic variations, favored in part by new theories on magnetohydrodynamics, as well as the limitations of the theories were presented. It was reported that, for magnetic pulsations, more study was needed to assess their origin and types as well as the role of the ionosphere on their transmission to the earth. On SSCs, it was deemed necessary to determine how the magnetic perturbation formed by a solar stream at a distance of a few earth radii was transmitted to the Earth and how it generated the polar currents that contributed to the formation of the recorded SSCs. Following these theoretical Sessions, three additional Sessions were held-two on Committee No. 10's work and one on the Atlas of Rapid Variations. The rules for the diffusion of the observations, given in the Symposium of Copenhagen, were confirmed. As requested by the Russians, a new phenomenon was added to the list of the parameters to be observed: the 'pearl pulsations' (Fig. 3) (pp) with a 14-s period, but its application was deferred until the Helsinki Assembly. It was decided to divide the pulsations in four groups-pp, pearl pulsations; pc, continuous pulsations; pt, train of pulsations; pg giant pulsations - and guidelines were established on how to report on their period and amplitude. The necessity of an accurate determination of the beginning of the events, mainly of the SSCs, was again urged. It was determined to ask the observatories to send copies of the magnetic events previously selected to be included in the atlas of real cases. A commission was appointed for the selection of the events on earth-currents that should also be included in the atlas.

In his report to the General Assembly of Helsinki (1960), Fr. Romañá mentioned the increment in the number of collaborating observatories which increased from 69 (in 1957) to 92 (in 1959). The Assembly adopted the resolutions of the Symposium of Utrecht and asked Committee No. 10 to determine the most important regions of the World for the distribution of observatories able to record pulsations. It was also recommended to organize a Symposium on rapid magnetic variations, mainly pulsations of periods lower than $20 \mathrm{~s}$, during the following IUGG Assembly.

The IAGA was comprehensively reorganized during the General Assembly of Berkeley (1963). The Association was organized into nine Commissions whose chairmen were to be proposed by the Executive Committee and 


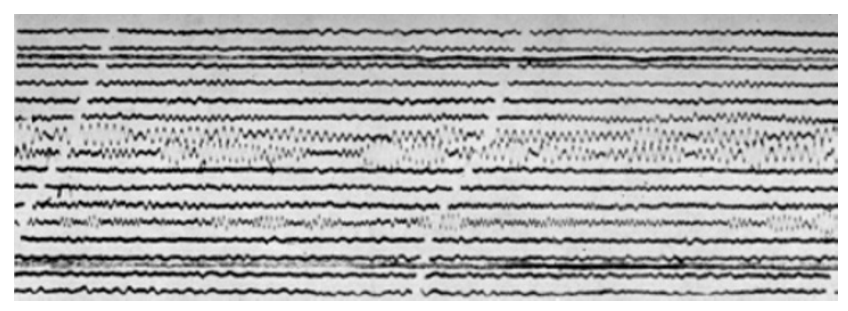

Fig. 3. Pearl pulsations at the Alma Ata observatory. Pearl pulsations belong to the characteristic elements of great magnetic storms microstructure and they occasionally coincide with bursts of X-rays in the atmosphere.

elected by the General Assembly. Each Commission had the authority to organize its activities into different Working Groups. The work of Committee No. 10 was included in Commission IV 'Magnetic Activity and Disturbances' within the framework of Working Group 8 'Morphology of Rapid Magnetic Variations', with Fr. Romañá as a Coordinator.

Fr. Romañá indicated to the Committee the decrease in the number of collaborating observatories (from 83 in 1960 to 52 in 1963) in his report to the Assembly. He also called two meetings to consider problems related to SSCs and pulsations. In the first meeting, he pointed out the necessity of sorting a series of observatories that were well distributed in latitudinal and longitudinal parameters, already equipped with convenient instrumentation to measure the SSC times accurately. The objective of the second meeting was to determine a correct classification of the magnetic pulsations. The decisions were included in Resolution 28 of IUGG and Resolution 13 of IAGA. The pulsations were divided in two classes: the regular ones, usually continuous, and the irregular ones. The first ones, with periods in the range 0.2-600 $\mathrm{s}$, were divided into five groups: pc $1,0.2-5 \mathrm{~s}$; pc $2,5-10$ s; pc 3, 10-45 s; pc 4, 45-150 s; pc 5, 150-600 s. The second class, usually connected with magnetic disturbances and related with the upper atmosphere, was divided in two groups: pi 1, 1-40 s, and pi 2 (previously called pt), 40-150 s. Thirty papers related to work of Committee No. 10 were presented at this Assembly.

In the General Assembly of St. Gall (1967), Fr. Romañá, as Coordinator of the Working Group IV-8, presented a report (Fig. 4) in which he indicated that the general activity of the WG during the period had been almost fully identified with its activity as a permanent service. He also presented the following problems, some of which are as yet still unsolved:

- Time of SSC and SI: from a study of the definitive data of the period 1958-1965, it can be deduced that they represented, in fact, the most probable value, but the accuracy was not better than $1 \mathrm{~min}$. He mentioned several causes, including the unavoidable subjectivity in the interpretation of the recorded curves.

- Time of bays and connected pulsations: the time given as the mean of all the data could not represent the most probable value of the initial moment of the event because it was not an instantaneous phenomenon as the SSC or SI. It is a kind of central weighted time around

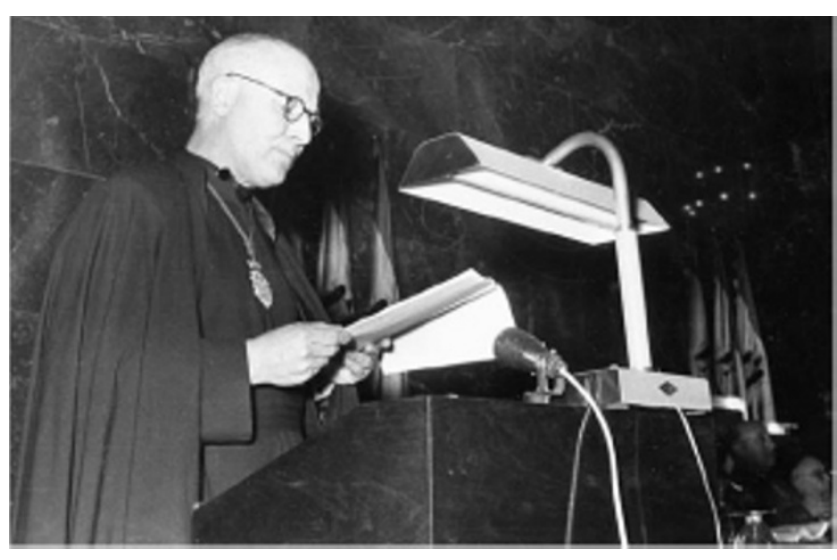

Fig. 4. Fr. Romañá in one of his scientific conferences. He was one of the promoters of the Service of Rapid Magnetic Variations and became the chairperson of the service for many years.

which the different manifestations of the event appear.

- Time of pulsations without bay: given the definition of the type pi pulsations, it was difficult to consider as the most probable the mean of the times given for different observatories. In fact, it was easy to mingle data corresponding to different trains of pulsations.

- Giant pulsations: the lack of precision in the definition made it difficult to distinguish these from other types of pulsations, such as pi or pc of higher amplitude.

- Solar flare effect: its study was difficult because of the lack of clear morphology.

Commission IV decided to join WG IV-1 and WG IV-8 in a unique WG IV-1 'Morphology and Indexes'. Fr. Romañá reported that the activity of Committee No. 10 during the last years had been a Service of Rapid Magnetic Variations inside the Geomagnetic Indexes Service, supported in part by the Federation of the Astronomic and Geophysical Services (FAGS). The Commission IV was a kind of Consulting Board of the Service. The aim of the Service was to obtain an image of the rapid magnetic variations and their characteristics in space and time.

In the General Assembly of Madrid (1969), the results of a questionnaire on the interest of participants for the different published lists of magnetic indexes and rapid magnetic variations were presented. The lists of SSC and Sfe were the most appreciated. The necessity to publish the exact time of SSC and SI that should provide the stations with rapid recorders was again emphasized.

Since 1970, RMV data had been published in IAGA Bulletins No. 32, Continuation of the Bulletins No. 12. The norms decided upon in the Madrid Assembly were introduced in Bulletin 32a; these omitted the 'minor disturbances' and the rejected Sfe. The SSC, SI, bays and pi2 were only given if enough reporting stations had recorded them. The pulsations pc4 and pc5 were to be published in the annual supplements of the quarterly bulletins. In addition, the checking lists were sent to obtain information only on pg and Sfe.

The following indications related to the recorded phenomena were given in the bulletins:

'SSCs are considered to be the sudden commencements 

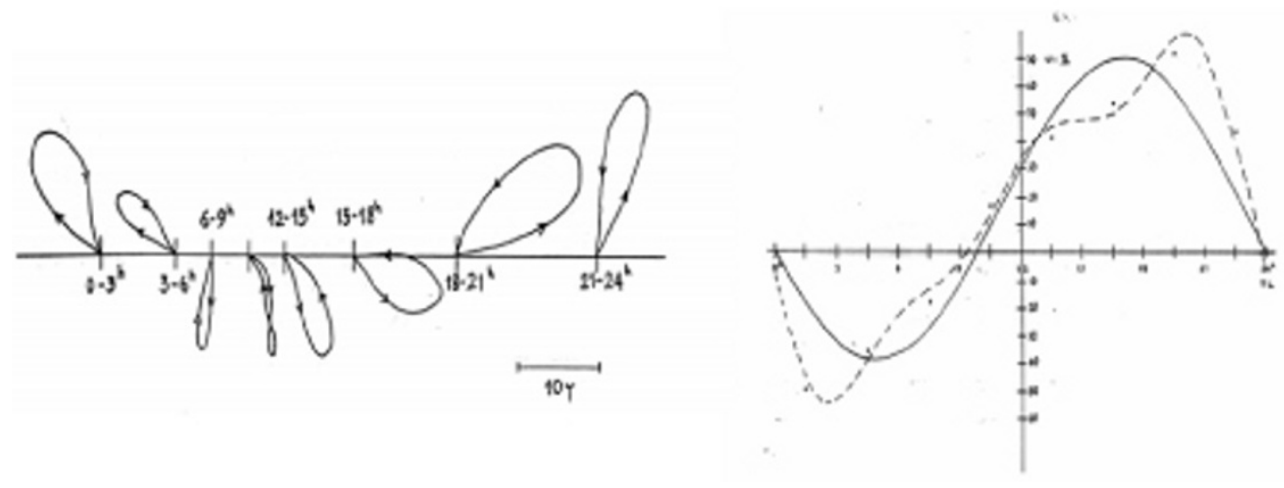

Fig. 5. (a) Anticlockwise rotation of the bay vector at Ebro Observatory (after Virgós and Cardús). For the H component, positive bays at night and negative during the day; for the D component, negative bays in the early morning and positive bays for the rest of the day. (b) Variation of the bay vector with local time having a minimum in the morning and a maximum in the afternoon. These results are compatible with the ionospheric electric currents described by Silsbee and Vestine (1942).

followed by a magnetic storm or by an increase of activity lasting at least $1 \mathrm{~h}$. Only cases reported by a minimum of ten stations are considered. However, the required number of stations varies in the regions with a low density of stations.

Bays or pulsations associated with bays. The same criterion is applied as that in the case of SSCs, related to the minimum number of reporting stations needed for their consideration. The following symbols are used to designate the different events:

b clear and isolated bay without pulsations or sudden commencement, during a quiet period;

bs bay with sudden commencement without pulsation;

bp bay with pulsations without sudden commencement; bps bay with pulsations and sudden commencement; pi2 train of pulsations of irregular shape and, generally, with sudden commencement, with a 40 - to 150 -s period, that appears with several series of oscillations each lasting about $10 \mathrm{~min}$;

pg giant pulsations; i.e., exceptional pulsations of large period and regularity;

$2 \mathrm{~b}$ pulsational disturbances of the pi2 type not associated to bays with periods in the range 40-180 s.

As far as Sfe is concerned, a list of probable Sfe and other lists with doubtful Sfe are published. Doubtful Sfe are considered to be those events not reported by stations well situated with respect to the sub-solar point as well as the events that - although they have been reported by stations well situated with respect to the sub-solar point-have also been reported by stations placed in deep night and cannot correspond to a night bay. In addition, the events whose interpretation is unclear because of universal simultaneous disturbances are also considered doubtful. Finally, if the solar, radio-electric, and ionospheric data do not show a clear variation at the time of the presumed Sfe, it is considered doubtful."

At this time, a paper on the rotation of the bay vector in Ebro Observatory and its variation with local time was published (Virgós and Cardús, 1974) that confirmed the succession law of bays found by Princep earlier and determined the angular velocity of bay vector as a constant at mid latitudes (Fig. 5).
A new significant change related with the RMV took place in the General Assembly of Grenoble (1975). The reorganization of the Association in the Assembly of Kyoto (1973) had placed the activity of the Service of RMV in Working Group 6 'Geophysical Indexes' inside Division V 'Observatories, Instruments, Indexes and Data'. A decision was made at the Assembly of Grenoble to deposit the archives of RMV used to prepare the IAGA Bulletin 33 in the Ebro Observatory. This Bulletin included the work of P. N. Mayaud (1973) which consisted of a list of 100 years of SSCs measured by the author using a criterion different from that standardly used until then, as defined above. The main difference had to do with the change of the concept of magnetic activity following the sudden impulse in the magnetic field. According to the author, the key to determining the existence of a SSC was the 'change of rhythm' of the magnetic activity after the sudden impulse as the former which would show the increase of this activity, independently of its amplitude. Mayaud also proposed determining the SSC by using records of five low-latitude observatories, not equatorial, regularly distributed around the globe. At these latitudes the auroral and equatorial electrojet disturbances were eliminated. The Assembly decided to use the new criterion for the new measures of SSCs so that the new data of the Service of RMV would continue the 100 years series assembled by Mayaud. Two resolutions related to RMV were approved of at this Assembly: (1) Resolution 5 thanked the Ebro Observatory for its long-term service in this field; (2) Resolution 6 asked the Observatory to continue to provide the list of SSC, Sfe, and unusual events for publication in Bulletin 32 and to discontinue the publication of pulsations, bays, and SI, once their production mechanism was sufficiently known. The procedure was to be supplemented by sending copies of magnetograms from selected low-latitude stations to Ebro Observatory upon request.

All of these rules were collected in Bulletin No 32g (with the data of 1976), the first volume to be published after the Grenoble Assembly. The selected low-latitude observatories were MB (Mbour), FQ (Fuquene), HO (Honolulu), PM (Port Moresby), and AL (Alibag), with TA (Tamanraset), PA (Paramaribo), AP (Apia), KY (Kanoya), and HY 

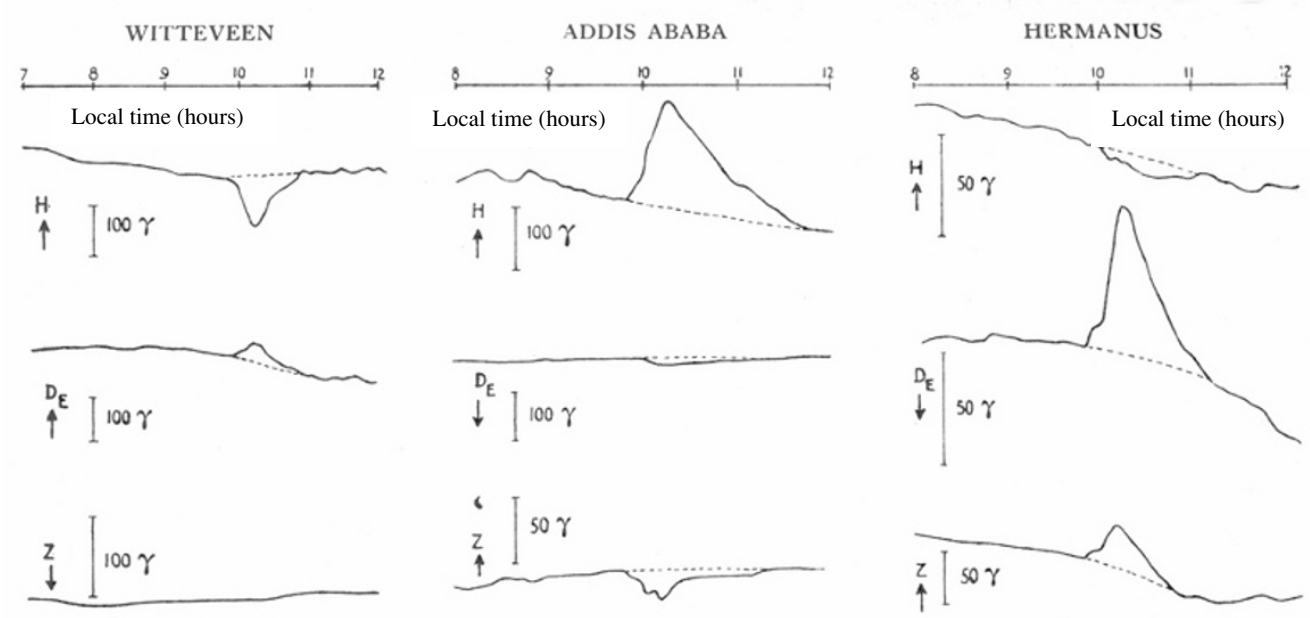

Fig. 6. Magnetograms from stations WIT, AAE, and HER showing the Sfe of March 23, 1958. Amplitude and sense of the magnetic variations depends on the position of the observatory with respect to the vortex of the current loop.

(Hyderabad) as supplementary stations. The data given for SSCs should be the hour and the mean value of the duration and amplitude recorded by the five observatories. To select the records it would be essential to use the list of possible SSCs provided by the general network of observatories. These data would also help solve the doubtful cases that resulted from the different morphology of the SSCs in the different low-latitude observatories. The work described in the Bulletin 39 (Mayaud and Romañá, 1977) was very useful for determining the procedure for carrying out the measurements with the Mayaud rules.

In the General Assembly of Seattle (1977), Working Group V-6 insisted on the necessity that as many observatories as possible report on possible detected SSCs to the Ebro Observatory in order to facilitate a better selection of SSCs to be published in the Bulletin 32.

In his report to the General Assembly of Edinburgh (1981), Fr. Cardús pointed out the scarcity of Sfe reporting observatories and their poor geographic distribution, with large zones, such as the American and Russian regions, empty of reporters. This fact resulted, on one hand, in difficulties in discerning the reality of the event and, on the other hand, in not detecting many Sfe. He also pointed out that there were observatories that reported consistently very clear Sfe during local night, contrary to what can be theoretically expected. The new classification system of Sfe, with letters indicating the event quality and numbers for the record quality, had been successful and helped clarify doubtful cases.

Fr. Cardús took over the direction of the Service with the publication of the 1980 data in the IAGA Bulletin $32 \mathrm{~g}$. He also pointed out in successive Assemblies the difficulty of determining Sfe, due to the lack of a clear definition of their morphology (Fig. 6) as well as the already mentioned decreasing number of reporting observatories. This lack of definition resulted in some stations classifying Sfe variations that cannot be classified in other groups.

Over the years the Ebro Observatory has expended a great deal of effort towards improving the definition of the phenomenon, as reflected in several papers and communica-

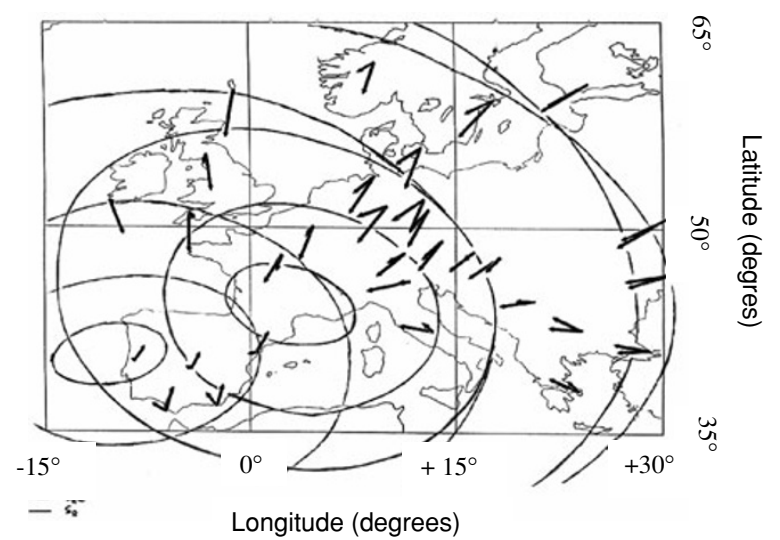

Fig. 7. Distribution of the equivalent ionospheric electric currents for the Sfe (eastern loop) and Sq (western loop) systems at 1200 hours on July 11, 1978 deduced from magnetic observations (after Curto et al., 1994a) Observatories between the foci of both vortices could have reversed Sfe (Sfe which produce a diminution of the regular variation).

tions. The most significant are by Curto et al. (1992), who reported the outstanding properties of the Sfe recorded at the Ebro Observatory, Curto et al. (1994a), who stated the conditions for the possibility of reversed Sfe, and Curto et al. (1994b), who provided a physical model, including the essential elements taking part in the Sfe production, from the solar flares to the magnetic field induced by the ionospheric currents in the dynamo region (Fig. 7).

The traditional method of detecting RMV takes a lot of time. This fact causes a diminution in the number of reporting observatories. A solution is foreseen in the utilization of new, automatic methods as much as possible. Along this line, at the General Assembly of Boulder (1995), J. J. Curto presented a system for the automatic detection of SSCs based on evaluating algorithms of magnetic fluctuation levels.

Fr. Alberca succeeded Fr. Cardús in 2000 as chairperson of the Service of Rapid Magnetic Variations. By taking advantage of the new facilities in data access provided by the 

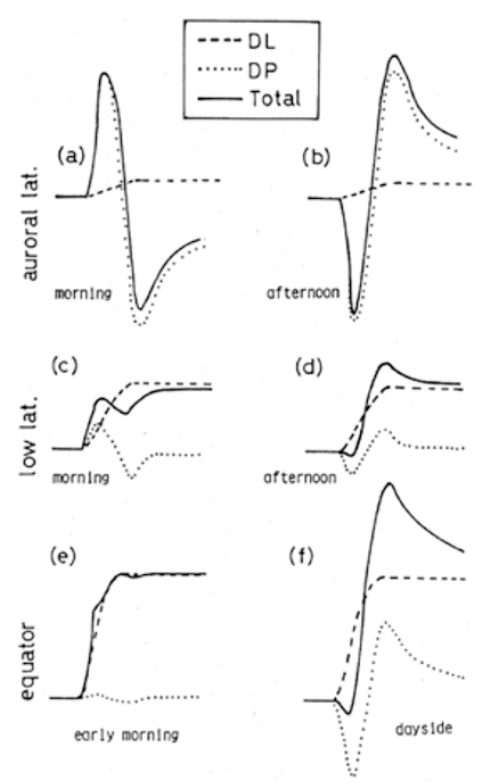

Fig. 8. Components of SSC events (according to Araki, 1994) and their manifestation according to the location of the observatory on the Earth: morning in high (a), low (c), and equatorial (e) latitudes or evening in high (b), low (d), and equatorial (f) latitudes. Two effects (low-latitude disturbance or DL associated to magnetopause currents and polar disturbance or DP associated to Field Aligned Currents) superpose, creating a complex morphology.

INTERMAGNET network, a modification was introduced on the procedure of data treatment. The 'checking lists' were no longer used for determining the Sfe. As a first step, the events taking place at times when no solar flare was reported were rejected from the lists sent by the reporting observatories. The data remaining were confirmed with a study of the registers of INTERMAGNET network accessible to the Observatory. The Service of RMV made the classification of the phenomenon with the traditional letters and numbers formerly provided by the reporting observatories. In this way, the discerning criterion was more uniform. To determine the region where the phenomenon was observable, global maps showing the lightened and dark zones were constructed. Finally, with all this data, the event was classified.

In the General Assembly of Sapporo (2003) J. J. Curto presented the actual strategies for SSC detection, comparing the traditional and the actual methods and showing a prospective of the future ones.

In a number of earlier communications, Fr. Cardús had demonstrated the ambiguity of the SSC denomination with respect to the actual rules for their classification as well as the unfitness of the given rules with the actual knowledge on the origin of SSCs. Several scientists (Joselyn and Tsurutani, 1990) agreed with these considerations and suggested changes in the classification of these events. More recently, Prof. Araki (1994) presented a physical model of the SSCs explaining every step of the SSC development from the initial compression of the magnetosphere by a sudden increasing of the dynamic pressure of the solar wind, the mechanism and morphology of the SSCs depending on the ionospheric conductivity, and the expected shape of the variation depending on the location of each magnetic observa- tory (Fig. 8).

The collection of data in the Service of RMV can help extend the study of these magnetic variations. With this in mind, the General Assembly of Upsala (1997) approved a resolution showing the deep appreciation for the work performed by the Ebro Observatory and recommended that every possible effort be made to continue the operation of and production of SSC and Sfe data.

In the General Assembly of Toulouse (2005) J. J. Curto reported on the progress in the automatic detection of SSCs and the convenience of using solar wind data as a complement for the observation of magnetic variations. The need for an automatic detection of SSCs in real time to alert forecasters and researchers of potential geomagnetic storm conditions was discussed by Joselyn (1985). More recently, the same need for mid-term forecast of magnetic storms has been pointed out by such authors as Khabarova et al. (2006) who used a moving gradient of the SYM-H index as detecting algorithm.

In this Assembly, J. J. Curto also proposed a change in the SSC classification to one following the terminology used in many recent works (Joselyn and Tsurutani, 1990). According to this system, the sudden increase in the magnetic field should be designed by the general term of sudden commencement SC, which can be named as SSCs if it is followed by a magnetic storm or as a SI if it is not. In fact, the two phenomena, SCs and magnetic storms, have different mechanisms and each can happen without the other. Although the scientific foundation of the proposal was accepted by most of the present scientists, it was decided to postpone the acceptance of the proposal to the next General Assembly to be held in Perugia (2007). At the same time, J. J. Curto was asked to produce a paper with the theoretical justification of the proposal with the aim of discussing it in the 2007 Assembly.

\section{Conclusions}

The Service of Rapid Magnetic Variations (RMV) of IAGA has proved to be a useful tool for improving the knowledge of these phenomena, usually through communications to IAGA Assemblies, but also by promoting specific meetings between concerned scientists, such as the Utrecht Symposium (1959). The Ebro Observatory has been one of the institutions closely involved in this task. In addition to its regular daily activities of providing reliable lists of events and creating normative prospects, the Service aims to focus the interest of the scientific community on this field and to promote the study of the physics of RMV. During the almost 90 years of its existence, the Service has made sustained efforts to go deep in the knowledge of these variations. As a result of the advances in the knowledge of their nature, more precise definitions have been proposed, which has resulted in the improvement of quality of the determinations. This evolution does not stop, and new, ongoing studies are going to push the limits of knowledge beyond what they are now.

\section{References}

Akasofu, S. I. and S. Chapman, The sudden commencements of geomagnetic storms, Urania, 44, 321-358, 1959. 
Araki, T., A physical model of the geomagnetic sudden commencement, Geophys. Monogr., 81, 183-200, 1994.

Bauer, L. A. (Editor), Transactions of Rome Assembly, May, 1922. Section of Terrestrial Magnetism and Electricity, Bull., 3, 170, 1923.

Bauer, L. A. and W. J. Peters, Regarding abruptly-beginning magnetic disturbances, Terr. Magnet. Atmos. Electric., 30, 45-68, 1925.

Chapman, S., On the Times of Sudden Commencements of Magnetic Storms, Proc. Phys. Soc. London, 30, 205-214, 1917.

Cirera, R., Noticia del Observatorio y de algunas noticias del eclipse, Memoria del Observatorio del Ebro no. 1, 1906.

Coulomb, J., Les théories des pulsations, Urania, 44, 163-183, 1959.

Curto, J. J., J. O. Cardús, J. M. Torta, C. Mazaudier, and M. Menvielle, 30 años de Sfe en el Observatorio del Ebro, Rev. Geofís., 48, 141-151, 1992.

Curto, J. J., C. Amory-Mazaudier, J. M. Torta, and M. Menvielle, Solar flare effects at Ebre: Regular and reversed solar flare effects, statistical analysis (1953 to 1985), a global case study and a model of elliptical ionospheric currents, J. Geophys Res., 99, 3945-3954, 1994a.

Curto, J. J., C. Amory-Mazaudier, J. M. Torta, and M. Menvielle, Solar flare effects at Ebre: Unidimensional Physical integrated model, J. Geophys. Res., 99, 23289-23296, 1994b.

De Voogt, A. H., Enregistrement direct des vecteurs de courant tellurique, Urania, 44, 263-270, 1959.

Joselyn, J. A., The automatic detection of geomagnetic-storm sudden commencements, Adv. Space Res., 5, 193-197, 1985.

Joselyn, J. A. and B. T. Tsurutani, Gemagnetic sudden impulses and storm sudden commencements. A note on terminology, EOS, 1808, 1990.

Khabarova, O., V. Pilpenko, M. J. Engebretson, and E. Rudenchik, Solar Wind and Interplanetary Magnetic Field Features Before Magnetic Storm Onset, Proc. Int. Substorms, 8, 1-6, 2006.

Mathias, E., Traité d'Électricité Atmosphérique et Tellurique, pp. 19-20, Mathias E. ed., Paris, 1924.

Mayaud, P. N., A hundred years series of Geomagnetic data 1868-1967: Indices aa and storm sudden commencements, IAGA Bull., 33, 1973.

Mayaud, P. N. and Romañá, A., Supplementary Geomagnetic Data 19571975: Indices Kn, Ks and Km, 1959-1963, Indices aa, 1968-1975, New list of ssc's 1968-1975, Yearly diagrams of activity 1957-1975, IAGA Bull., 39, 1977.

Rodés, L., On the non-simultaneity of magnetic storms, Terr. Magnet. Atmos. Electric., 27, 161-166, 1922.

Rodés, L., Yearly and daily period on the frequency of sudden commencements of magnetic storms. C R Assemb Lisbonne. 279-282. U.G.G.I. Association of Terrestrial Magnetism and Electricity, Bull., 9, 1934.

Rodés, L., Report to the President of the Committee on Sudden Commencements. Transactions of Edinburg Meeting. 177-179. U.G.G.I. Association of Terrestrial Magnetism and Electricity, Bull., 10, 1937.

Romañá, A., Sur le caractère général de la loi de classification des baies géomagnétiques pour les latitudes moyennes. Transactions of Brussels Meeting, IATME Bull., 14 (Summary), 1954.

Romañá, A., "Report General" with the Provisional Atlas of Rapid Variations, Ann. Int. Geophys. Year, 2B, 668-709, 1959.

Silsbee, H. B. and E. M. Vestine, Geomagnetic bays, their frequency and current systems, Terr. Magnet. Atmos. Electric., 47, 197-208, 1942.

Tanakadate, A., Report of the Committee on Investigation on Sudden Commencements of Magnetic Storms. Comptes Rendus de 1'Assemblée de Prague, UGGI Bull., 7, 56-57, 1927.

Transactions of Madrid Assembly, October 1924, Section of Terrestrial Magnetism and Electricity, Bull., 5, Baltimore, Maryland 1925.

Transactions of Oslo Meeting. August 19-28, IATME Bull., 13, pg 538, Washington D.C. 1950, 1948.

Transactions of the Rome Meeting. September 14-25, IAGA Bull., 15, Copenhagen 1957, 1954.

Transactions of the Toronto Meeting, September 3-14, IAGA Bull., 16, 329-338, 343-347, Copenhagen 1960, 1957.

Veldkamp, J. and D. Van Sabeen, On the current system of solar flare effects, Urania, 44, 362-374, 1959.

Virgós, J. and J. O. Cardús, Velocidad de rotación del vector bahía, Urania, 279-289, 97-112, 1974.

J. J. Curto (e-mail: jjcurto@obsebre.es), J. O. Cardús, L. F. Alberca, and E. Blanch 